\title{
Subcomponents of the cervical evoked response in patients with intracerebral circulatory arrest
}

\author{
T GANES, P NAKSTAD \\ From the Laboratory of Clinical Neurophysiology, Department of Neurology, and Section of \\ Neuroradiology, Department of Radiology, Rikshospitalet, Oslo, Norway
}

SUMmARY The subcomponents of the cervical evoked response, $\overline{\mathrm{N} 11}, \overline{\mathrm{N} 13}, \overline{\mathrm{N} 14}$, and the following positivity, were studied in 13 patients with full arrest of the intracerebral circulation, isoelectric EEGs and abolished cortical somatosensory evoked responses. The peak negativity ( $\overline{\mathrm{N} 13})$ and the following positive wave were present in all patients. Also $\overline{\mathrm{N} 11}$ and $\overline{\mathrm{N}} 14$ could be identified in most patients either at standard stimulation frequency $(2 \mathrm{~Hz})$ or by increasing the stimulation rate. The results point to a spinal origin of these sub-components in the human cervical evoked response.

The human cervical evoked responses, recorded from the neck, typically consists of an initial small positive deflection, a following large negative wave and a final relatively wide positive potential. The peak of the negativity, $\overline{\mathrm{N} 13}$, generally is preceded by a small notch, $\mathrm{N} 11$, on the ascending negativity and is followed by another small inflection, $\overline{\mathrm{N} 14}$, on the descending negative slope..$^{1-5}$ Various mechanisms have been proposed for each of these subcomponents. ${ }^{1-19}$

The cervical evoked response is used extensively in clinical diagnostic neurology either alone or with the plexus and cortical evoked responses to determine the central afferent conduction times. ${ }^{20-30} \mathrm{~A}$ full knowledge of the mechanisms and site of origin of the different components in this response therefore evidently is of value.

In the present investigation the various components of the cervical evoked response were examined in a sample of 13 carefully selected patients with maintained cervical evoked responses but extinguished cortical responses, isoelectric EEGs and complete arrest of intracerebral circulation. The purpose of the study was to determine which subcomponents of the human cervical evoked response were of spinal and which of intra-cerebral origin with particular emphasis on the $\overline{\mathrm{N} 14}$ and the following positivity.

Address for reprint requests: T Ganes, Department of Neurology, Rikshospitalet, Oslo 1, Norway.

Received 13 March 1983 and in final revised form 19 August Accepted 14 September 1983

\section{Materials and methods}

\section{Materials}

The patients comprised 13 subjects out of a larger group of comatose patients examined with somatosensory evoked potential (SEP) and EEG. The criteria for the present sample were that the cortical evoked responses should be bilaterally abolished while the plexus and cervical responses be well preserved. The EEG taken simultaneously should be isoelectric and four vessel selective high pressure cerebral angiography showing complete arrest of intracerebral circulation should have been performed before or within a maximum of three hours after the EEG and SEP tests. Age and the main diagnostic groups of the patients are shown in table 1 . The four patients under the diagnostic column "other" comprise two with complete cerebral infarction after an intracerebral haemorrhage, one with a postoperative cerebral herniation and one with cerebral herniation of unknown aetiology.

\section{Stimulation}

The median nerve was stimulated percutaneously either in the wrist or in the elbow. A bipolar commercially available "saddle" electrode (Medelec)) was used for stimulation and the stimuli were delivered by a Medelec IS/V stimulator. Stimulus strength were $150-200 \mathrm{~V}$, duration $0.2 \mathrm{~ms}$. Generally $300-1000$ stimuli were delivered to each nerve at standard frequency of $2 \mathrm{~Hz}$. High frequency stimulation $(10-50 \mathrm{~Hz})$ were performed in 10 patients to enhance N11 and $\bar{N} 14 .{ }^{1}$

\section{Recording}

The responses were simultaneously recorded and averaged from the brachial plexus $(\overline{\mathrm{N} 9})$, the neck $6-8 \mathrm{~cm}$ proximal to the 7th cervical spina and from the contralateral hand projection area on the scull (approximately corresponding to $\mathrm{P}_{3}$ or $\mathrm{P}_{4}$ in the 10-20 international EEG system). The 
Table 1 Age, sex and the main diagnostic groups of the patients

\begin{tabular}{|c|c|c|c|c|c|c|c|}
\hline \multirow[t]{2}{*}{$\overline{N o}$} & \multicolumn{2}{|l|}{ Sex } & \multicolumn{2}{|l|}{ Age } & \multicolumn{3}{|c|}{ Main diagnostic group } \\
\hline & $\overline{\text { Male }}$ & Female & Median & Range & $\begin{array}{l}\text { Subarachnoid } \\
\text { haemorrhage }\end{array}$ & Head trauma & Other \\
\hline$\overline{13}$ & 8 & 5 & 25 & $9-69$ & 3 & 6 & 4 \\
\hline
\end{tabular}

common reference electrode was placed on the forehead. This reference location was used since the subcomponent $\mathrm{N} 14$ is most conspicuous with the reference electrode on the scull $^{10}$ and the following positivity is also relatively prominent with a scull reference. Furthermore, our normative data were based on this reference location. ${ }^{1} 22$

Commercially available $\mathrm{Ag} / \mathrm{AgC1}$ electrodes were used for recording, in the scull bentonite was added to keep the electrodes in situ. The signals were recorded and averaged on a modified Medelec MS6 electrophysiological system. High and low pass filters were set to $16 \mathrm{~Hz}$ and $3 \cdot 2 \mathrm{KHz}$ respectively. Most of the SEP records were taped on a multichannel FM tape recorded for later detailed analysis.

\section{Results}

The main negative component of the cervical evoked response (as defined by the selection criteria) was present in all patients, while the cortical evoked responses invariably were extinguished bilaterally.

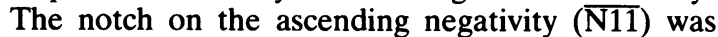
easily identified in most patients at standard stimulation frequency of $2 \mathrm{~Hz}$.

The notch $(\overline{\mathrm{N} 14})$ on the descending negativity was present in eight out of the 13 patients and generally seen as a very small inflection at standard stimulation frequency. The latencies between the peak of $\overline{\mathrm{N} 9}$ and $\overline{\mathrm{N} 11}, \overline{\mathrm{N} 13}$ and $\overline{\mathrm{N} 14}$ respectively are given in table 2 . The results were based on 10 tests in eight patients. Since $\overline{\mathrm{N} 14}$ frequently was inconspicious exact determination of the $\overline{\mathrm{N} 9}-\overline{\mathrm{N}} 14$ time often was difficult. The normative data were taken from a previous investigation of the human cervical evoked response. ${ }^{1}$

When the stimulation rate was increased $(10-50$ $\mathrm{Hz}$ ), the amplitude of the main negative wave ( $\overline{\mathrm{N} 13})$ typically was reduced while $\overline{\mathrm{N} 11}$ and $\overline{\mathrm{N} 14}$ were relatively enhanced often being visible as small separate potentials. The identification rate of each subcomponent at standard and high frequency stimulation is given in table 3 . A distinct positive wave following the main negative wave was present in all patients tested (table 3). Two examples of the responses obtained are shown in figs 1 and 2 .

The data in fig 1 were from a 24 -year-old male patient with severe head injuries after a traffic accident. When SEP and EEG were recorded he had clinical signs of cerebral herniation: no respiration, dilated nonreactive pupils, no vestibulo-ocular reflexes. His EEG (fig 1A) was isoelectric and the SEP test (fig 1B) showed no cortical responses. The
Table 2 Peak to peak latencies between the plexus evoked responses (N9) and the different subcomponents of the cervical evoked responses at $2 \mathrm{~Hz}$ stimulation rate. The normative data were taken from a previous study. ${ }^{.}$

\begin{tabular}{llllll}
\hline & \multicolumn{2}{l}{ Latencies (ms) } \\
\cline { 2 - 3 } & \multicolumn{2}{l}{ Normative data } & & \multicolumn{2}{l}{ Patient data } \\
\cline { 2 - 3 } \cline { 5 - 6 } & $\bar{x}$ & $\pm S D$ & & $\bar{x}$ & $\pm S D$ \\
\hline N9-N11 & 2.05 & 0.3 & & 1.98 & 0.47 \\
N9-N13 & 3.3 & 0.28 & & 3.41 & 0.4 \\
N9-N14 & 4.38 & 0.29 & & 4.73 & 0.58 \\
\hline
\end{tabular}

cervical responses were, however, present and all subcomponents: $\overline{\mathrm{N} 11}, \overline{\mathrm{N} 13}, \overline{\mathrm{N}} 14$ and the ensuing positivity, could be identified at standard stimulation frequency. When the stimulation rate was increased (fig 1C) $\overline{\mathrm{N} 11}$ and $\overline{\mathrm{N} 14}$ were enhanced relatively to the N13. Four vessel selective high pressure cerebral angiography (fig 1D) was performed $2 \frac{1}{2}$ hours after the SEP and EEG and showed full arrest of all intracranial circulation.

The second example (fig 2) was taken from a 15year-old boy with severe head injuries after a traffic accident. His EEG (not displayed in the figure) was isoelectric and the SEP test (fig 2B) showed bilaterally extinguished cortical responses. The cervical evoked response was present and of normal amplitude $(>1 \mu \mathrm{V})$. The subcomponents $\overline{\mathrm{N} 11}$ and $\mathrm{N} 14$ were, however, difficult to identify being visible as minor inflections on the rising and falling negativity at standard $2 \mathrm{~Hz}$ stimulation. Increasing the stimulation rate produced a typical reduction of $\overline{\mathrm{N} 13}$ while $\overline{\mathrm{N} 11}$ and $\mathrm{N} 14$ were enhanced being visible as separate small potentials (fig $2 \mathrm{C}$ ). Four vessel selective cerebral angiography was performed 30 minutes after the SEP and EEG test and verified a full intracerebral circulatory arrest (fig 2A).

\section{Discussion}

The human cervical evoked response recorded from the surface of the neck comprise several subcomponents, the generation site and mechanisms of which are still debated. Previous experimental studies in humans have emphasised the similarity between the cervical evoked response and the spinal cord potentials obtained in experimental animals. ${ }^{146}$

Most human data ${ }^{1-2}{ }^{4-6-19}$ point to $\overline{\mathrm{N} 11}$ and $\overline{\mathrm{N} 13}$ 
Table 3 Identification ratio of the different subcomponents at standard $2 \mathrm{~Hz}$ stimulation and at higher stimulation frequencies

\begin{tabular}{clllll}
\hline Stim mode & No. & \multicolumn{5}{c}{ Subcomponents of cervical evoked SEP } \\
\cline { 3 - 6 } & & $\overline{N 11}$ & $\overline{N 13}$ & $\overline{N 14}$ & Pos wave \\
\hline $2 \mathrm{~Hz}$ & 13 & 10 & 13 & 8 & 13 \\
$10-50 \mathrm{~Hz}$ & 10 & 10 & - & 9 & - \\
\hline
\end{tabular}

as potentials of spinal origin. Thus, $\overline{\mathrm{N} 11}$ probably reflects activity in the primary afferent fibres either in the dorsal root entry zone or in the dorsal columns, while $\overline{\mathrm{N} 13}$ evidently has a post-synaptic origin ${ }^{1}$ and probably corresponds to the $\overline{\mathrm{N} 1}$ wave of the dorsal cord potential of animals which is produced by synaptic activity in the middle layers of the dorsal horn. ${ }^{31-37}$ The present data, showing that $\overline{\mathrm{N} 11}$ and $\overline{\mathrm{N} 13}$ were present in most patients with full arrest of the intracerebral circulation further confirmed the spinal origin of these subcomponents. Few investiga- tions have explicitely studied $\overline{\mathrm{N} 14}$ and the following positive wave. $\overline{\text { N14 }}$ generally is very small and may even in healthy cooperative subjects be inconspicuous or absent at standard stimulation frequency ( 2 $\mathrm{Hz}){ }^{1}$

Both $\overline{\mathrm{N} 14}$ and the following positivity have been related to far field potentials of intracerebral origin,,$-710-11161719$ an assumption based either on clinical neurological data or from variations in the cervical evoked response obtained in healthy subjects with different electrode positions. Inferring the generator site of a local intracerebral or spinal potential from variations in the surface recorded "far field" potentials is however at best an uncertain method since it is often virtually impossible to predict the geometrical surface "far field" distribution of a given local intracerebral potential.

On the other hand, the fact that $\overline{\mathrm{N} 14}$ and the following positivity in humans also are present in the well known spinal cord potential in experimental

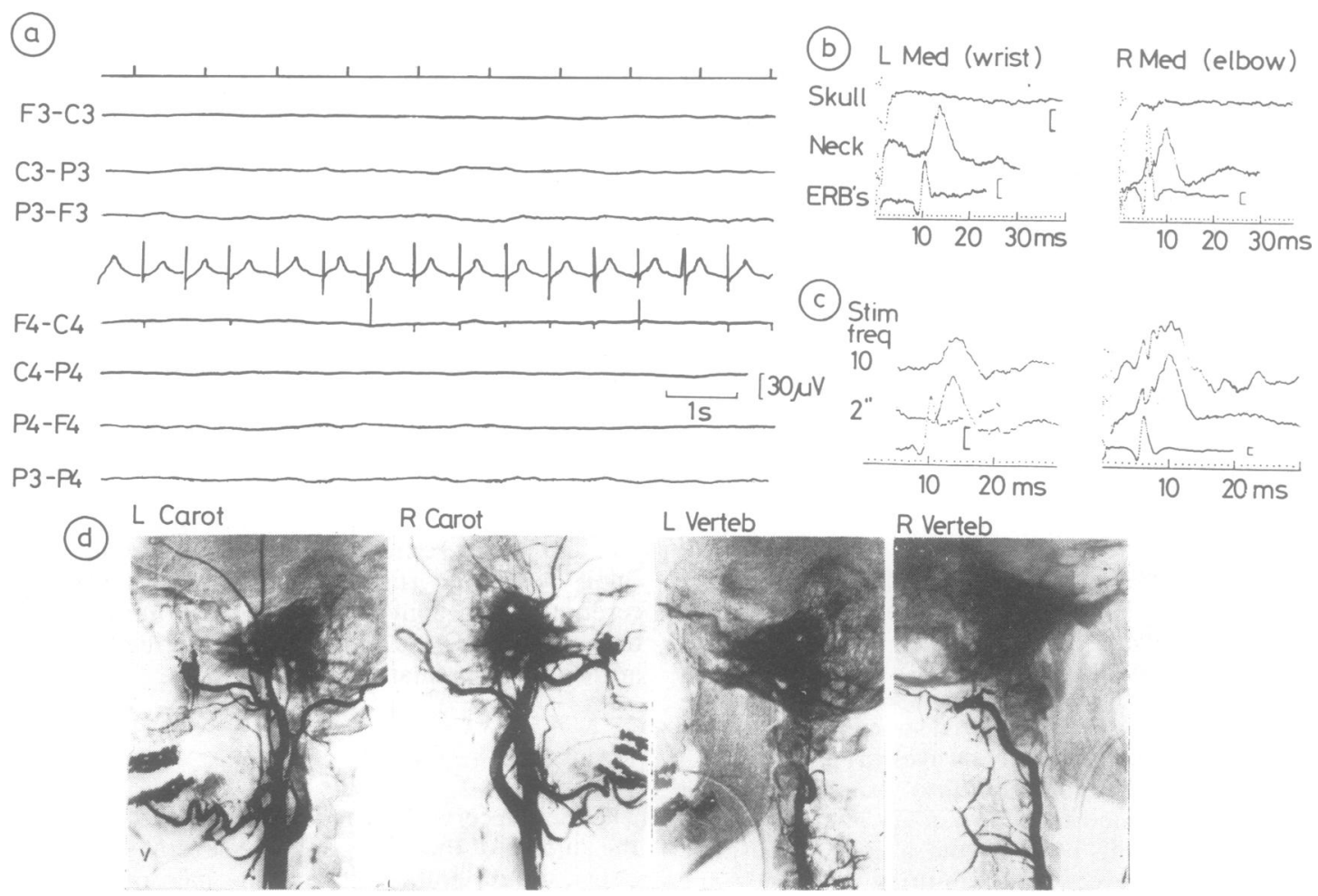

Fig 1 Records from a patient with cerebral herniation. A: EEG B: SEP recorded simultaneously from Erb's, neck and skull at standard stimulation frequency of $2 \mathrm{~Hz}$. C: The cervical evoked responses at standard and $10 \mathrm{~Hz}$ stimulation. Lower record represent the plexus response. Note that the lower calibration line in $B \& C(2.5 \mu \mathrm{V})$ is for the plexus responses only. Calibration for the cortical and cervical responses $(2.5 \mu \mathrm{V})$ is given by the uppermost line in $B$. D: Selective four vessel cerebral angiography in the same patients $2 \frac{1}{2}$ hours after the EEG and SEP records. 


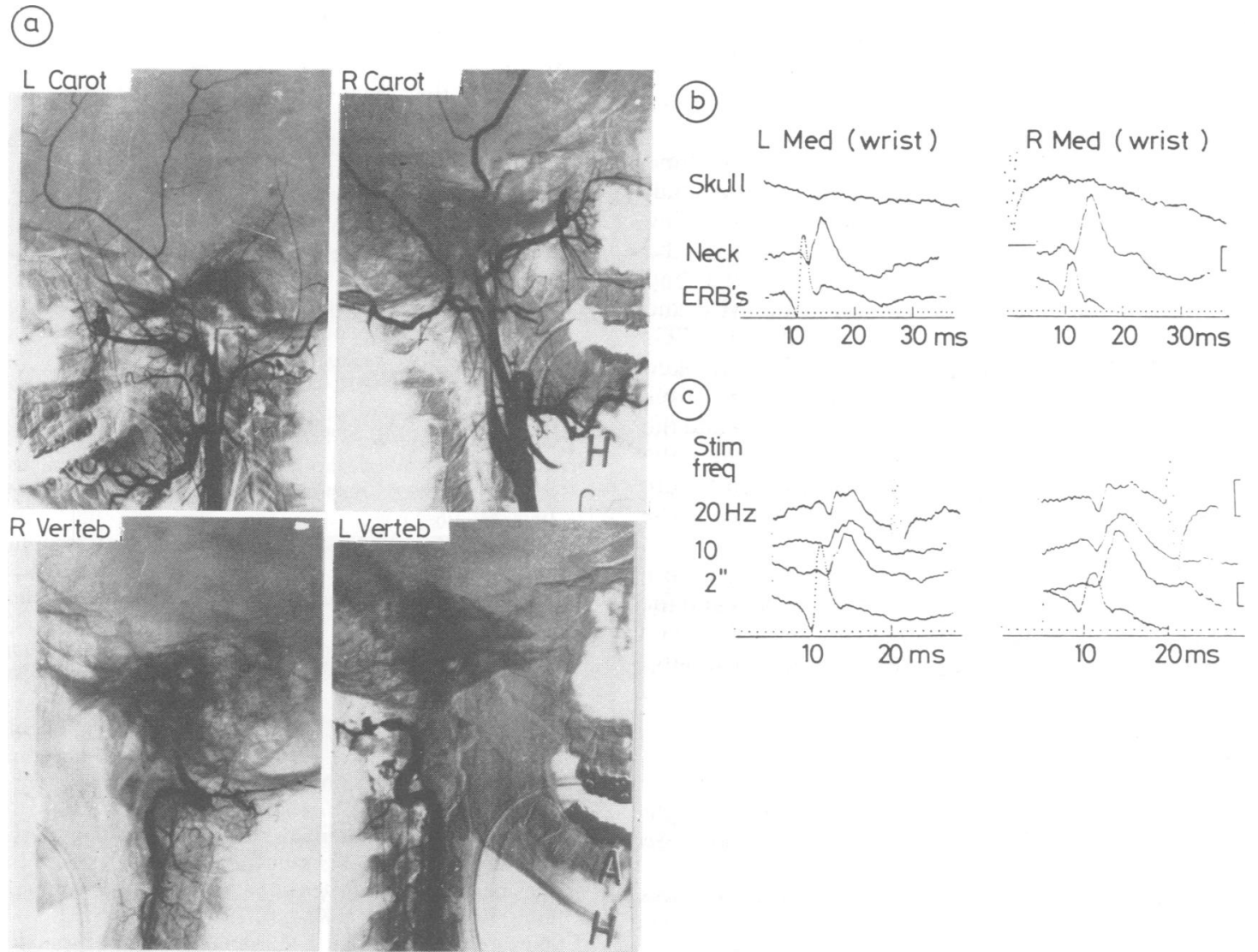

Fig 2 Enhancement of $\overline{N 1}$ and $\overline{N 14}$ by high frequency stimulation. A: Selective four vessel cerebral angiography. B: SEP recorded from Erb's point, neck and skull at standard $2 \mathrm{~Hz}$ stimulation. Note the inconspicuous $\mathrm{NII}$ on both sides and the non-visible $N 14$ on the right side. C: Effect of high frequency stimulation on the cervical evoked response. Note the relative enhancement of $\overline{N 11}$ and $\overline{N 14}$ and the reduction of $\overline{N 13}$. The SEP records in $B$ and $C$ were taken 30 minutes before the cerebral angiography in A. Calibration lines represents $2.5 \mu \mathrm{V}$.

animals, does not automatically imply a common mechanism.

Recent experimental data from humans,' using conventional neurophysiological test techniques such as resistance to high frequency stimulation, effect of paired stimuli and graded stimulus strength have however confirmed that $\overline{\mathrm{N} 14}$ and the following positive wave in humans have many properties in common with the $\overline{\mathrm{N} 2}$ notch and following positivity in experimental animals.

Based on these data it has been proposed that $\overline{\mathrm{N} 14}$ represented a potential generated in the spinal cord by (presynaptic) activity in a group of relatively slow conducting high threshold afferent fibres. ${ }^{1}$

The present data gave more direct support for a spinal origin of $\overline{N 14}$, showing that this notch was present in eight out of the 13 patients examined when standard $2 \mathrm{~Hz}$ stimulation rate was used. Furthermore, $\mathbf{N 1 4}$ was typically enhanced ${ }^{1}$ and readily seen as a small separate potential in almost all patients (nine of 10) when the stimulus frequency was increased.

Experiments on the human cervical evoked response have indicated that the positive wave following after the main negative wave, represents an inhibitory mechanism ${ }^{18}$ with many parallells to the dorsal root potential (DRP) studied in experimental animals. ${ }^{33}{ }^{3640}$ The present investigation also provided arguments for the positive wave being a spinal cord potential since it was invariably present in all patients examined although their intracerebral circulation was arrested, their EEGs isoelectric and the cortical somatosensory evoked responses extinguished. This does not exclude, however, that far 
field potentials of intracerebral origin normally may contribute to this positivity of the cervical evoked potential. In fact the amplitude of the positive wave generally was larger in normal subjects compared to the present group of patients.

The possibility that some of the patients at the time of the SEP and EEG tests should have had a small intracranial residual-perfusion and thus functioning intracerebral structures giving rise to $\overline{\mathrm{N} 14}$ or the positive wave seems unlikely. All patients had clinical signs of cerebral herniation at the SEP and EEG examination time, and the fact that their EEGs invariably were isoelectric and the cortical evoked responses extinguished probably are incompatible with residual intracerebral function. The $\overline{\mathrm{N} 14}$ and the positive wave also were present in patients where the final four vessel angiography was performed before or immediately after the SEP and EEG records (fig 2).

Based on the present data we therefore propose that the main subcomponents $\overline{\mathrm{N} 11}, \overline{\mathrm{N} 13}, \overline{\mathrm{N} 14}$ and the following positive wave in the human cervical evoked response are all integral parts of this response, generated in the spinal cord.

\section{References}

${ }^{1}$ Ganes T. Synaptic and non-synaptic components of the human cervical evoked response. J Neurol Sci 1982;55:313-26.

2 Jones SJ. Short latency potentials recorded from the neck and scalp following median nerve stimulation in man. Electroencephalogr Clin Neurophysiol 1977;43:853-63.

${ }^{3}$ Matthews WB, Beauchamp M, Small DG. Cervical somatosensory evoked responses in man. Nature 1974;252:230-2.

${ }^{4}$ Shimoj K, Matuski M, Shimuzu H. Wave form characteristics and spatial distribution of evoked spinal electrogram in man. J Neurosurg 1977;46:304-13.

${ }^{5}$ Shimoj K, Shimizu M, Marugama Y. Origin of somatosensory evoked responses recorded from the cervical skin surface. J Neurosurg 1978;48:980-4.

${ }^{6}$ Allison T, Hume A. A comparative analysis of short latency somatosensory evoked potentials in man, monkey, cat and rat. Exp Neurol 1981;72:592-611.

${ }^{7}$ Azinska BJ, Cracco RQ. Short latency somatosensory evoked potentials in brain dead patients. Arch Neurol 1980;37:222-5.

${ }^{8}$ Chaippa KH, Young RR, Goldie WD. Origins of the components of human shortlatency somatosensory evoked responses (SER). Neurology (Minneap) 1979;29:558.

${ }^{9}$ Cracco RQ, Bickford RG. Somatomotor and somatosensory evoked responses. Arch Neurol 1968;18:52-68.

${ }^{10}$ Desmedt JE, Cheron G. Central conduction in man: neurol. generators and interpeak latencies of the far field components recorded from neck and right or left scalp and earlobes. Electroencephalogr Clin Neurophysiol 1980;50:382-403.
${ }^{11}$ Desmedt JE, Cheron G. Prevertebral (oesophageal) recording of subcortical somatosensory evoked potentials in man: the spinal P13 component and the dual nature of the spinal generators. Electroencephologr Clin Neurophysiol 1981;52:257-75.

${ }^{12}$ Dimitrijevic MR, Sedgwick EM, Sherwood A, Soar JS. A spinal cord potential in man. $J$ Physiol (Lond.) 1980;303:37.

${ }^{13}$ El-Negamy E, Sedgwick EM. Properties of a spinal somatosensory evoked potential in man. $J$ Neurol Neurosurg Psychiatry 1978;41:762-8.

${ }^{14}$ Ertekin C. Studies on the human evoked electrospinogram, Part I (The origin of the segmental evoked potential). Acta Neurol Scan 1976;53:3-20.

${ }^{15}$ Hume AL, Cant BR. Conduction time in central somatosensory pathways in man. Electroencephalogr Clin Neurophysiol 1978;45:361-75.

${ }^{16}$ Kritchevsky M, Wiederholt WC. Short latency somatosensory evoked responses in man. Arch Neurol 1978;35:706-11.

${ }^{17}$ Lesser RP, Koehle R, Lueders H. Effect of stimulus intensity on short latency somatosensory evoked potentials. Electroencephalogr Clin Neurophysiol 1979;47:377-82.

${ }^{18}$ Shimoj K, Matsuki M, Ito Y, et al. Interactions of human cord dorsum potentials. J Appl Physiol 1976;40:79-84.

${ }^{19}$ Stöhr M, Riffel B. Short latency somatosensory evoked potentials to median nerve stimulation: Components N13-P13, N14-P14, P15, P16 and P18 with different recording methods. $J$ Neurol 1982;228:39-47.

${ }^{20}$ Chiappa KH, Choi S, Young R. Short latency somatosensory evoked potentials following median nerve stimulation in patients with neurological lesions. In: Desmedt JE, ed. Progress in Clinical Neurophysiology, Vol. 7. Basel: S Karger, 1980.

${ }^{21}$ El-Negamy E, Sedgwick EM. Delayed cervical somatosensory potentials in cervical spondylosis. $J$ Neurol Neurosurg Psychiatry 1979;42:238-41.

${ }^{22}$ Ganes T. A study of peripheral, cervical and cortical evoked potentials and afferent conduction times in the somatosensory pathways. Electroencephalogr Clin Neurophysiol 1980;49:446-51.

${ }^{23}$ Ganes T. Somatosensory conduction times and peripheral, cervical and cortical evoked potentials in patients with cervical spondylosis. J Neurol Neurosurg Psychiatry 1980;43:683-9.

${ }^{24}$ Ganes T. Somatosensory evoked responses and central afferent conduction times in patients with multiple sclerosis. J Neurol Neurosurg Psychiatry 1980;43: 948-53.

${ }^{25}$ Hume AL, Cant BR, Shaw NA. Central somatosensory conduction time in comatose patients. Ann Neurol 1979;5:379-84

${ }^{26}$ Jones SJ. Investigation of brachial plexus traction lesions by peripheral and spinal somatosensory evoked potentials. J Neurol Neurosurg Psychiatry 1979;42:107-16.

${ }^{27}$ Lindsay KW, Carlin J, Kennedy I, Fry J, McInnes A Teasdale GM. Evoked potentials in severe head injury: analysis and relation to outcome. $J$ Neurol Neurosurg Psychiatry 1981;44:796-802.

${ }^{28}$ Small DG, Matthews WB, Small M. The cervical somatosensory evoked potential in the diagnosis of 
multiple sclerosis. J Neurol Sci 1978;35:211-24.

${ }^{29}$ Symon L, Hargadine J, Zawinski M, Branston N. Central conduction times as an index of ischemia in subarachnoidal hemorrhage. J Neurol Sci 1979;44: 95-103.

${ }^{30}$ Stöhr M, Buettner UW, Riffel B, Koletzki E. Spinal somatosensory evoked potentials in cervical cord lesions. Electroencephalogr Clin Neurophysiol 1982; 54:257-65.

${ }^{31}$ Beall JV, Applebaum AE, Foreman RD, Willis WD. Spinal cord potentials evoked by cutaneous afferents in the monkey. J Neurophysiol 1977;40:199-211.

${ }^{32}$ Bernhard CG. The spinal cord potentials in leads from the cord dorum in relation to peripheral source of afferent stimulation. Acta Physiol Scand 1953. Suppl. 106:1-29.

${ }^{33}$ Bernhard CG, Widen L. On the origin of the negative and positive cord potentials evoked by stimulation of low threshold cutaneous fibres. Acta Physiol Scand 1953: Suppl. 106:42-54.

${ }^{34}$ Coombs JS, Curtis DR, Landgren S. Spinal cord poten- tials generated by impulses in muscle and cutaneous afferent fibres. $J$ Neurophysiol 1956;19:452-67.

${ }^{35}$ Gasser HS, Graham HT. Potentials produced in the spinal cord by stimulation of dorsal roots. Am J Physiol 1933;103:303-20.

${ }^{36}$ Willis WD, Coggeshall RE. Sensory Mechanism of the Spinal Cord. Chichester: John Wiley \& Son, 1978.

37 Yates BJ, Floyd BS, Thompson FJ, Parker-Mickle J. Origin and properties of spinal cord field potentials. Neurosurgery 1982;11:439-50.

${ }^{38}$ Eccles JC, Magni F. Central inhibitory action produced by muscle afferent volleys. $J$ Physiol (Lond.) 1961;159:147-66.

${ }^{39}$ Eccles JC, Kostyuk PG, Schmidt RF. Presynaptic inhibition of the central actions of flexor reflex afferents. J Physiol (Lond.) 1962;161:258-61.

${ }^{40}$ Eccles JC, Schmidt RF, Willis WD. Depolarization of the central terminals of cutaneous afferent fibres. $J$ Neurophysiol 1963;26:646-61. 